Revista de Ciencias Sociales - Número 67 (2015) - Páginas 193-210

Defendamos la escuela democrática

\title{
DEFENDAMOS LA ESCUELA DEMOCRÁTICA
}

\author{
PIERO CALAMANDREI*
}

\section{¡Queridos colegas!}

Estamos aquí docentes de todas las categorías escolares, desde las escuelas primarias a las universidades, hermanados en este ejercicio cotidiano de altruismo, en esta devoción diaria por el mañana, por el porvenir que preparamos y que no veremos, que es la enseñanza. Estamos aquí reunidos en este congreso que se titula «En defensa de la escuela».

* Traducción y notas de José Luis Guzmán Dalbora, profesor titular de Derecho penal e Introducción a la Filosofía moral y jurídica en la Universidad de Valparaíso (Chile).

El original italiano, Difendiamo la scuola democratica, corresponde al discurso pronunciado por Piero Calamandrei (Florencia, 1889-1956) en el III Congreso de la Asociación de Defensa de la Escuela Nacional realizado en Roma el 11 de febrero de 1950. Se publicó en el periódico Scuola democratica, Roma, IV, suplemento del número 2, 20 de marzo de 1950, págs. 1-5. Décadas más tarde aparecerá como capítulo de uno de los libros póstumos que recogen los escritos del autor acerca del tema, Per la scuola, Introduzione de Tullio De Mauro, Nota storico-bibliografica de Silvia Calamandrei, Sellerio Editore, Palermo, 2a ed., 2011 (EAN 978-88-389-2356-4), págs. 81-106. Agradecemos a los herederos de Calamandrei y a la editorial Sellerio haber cedido gratuitamente los derechos para la traducción castellana del discurso.

Éste se inscribe en una antigua y persistente inquietud del jurista toscano por la educación, particularmente la institución de una auténtica escuela pública, que él consideraba elemento neurálgico de la democracia, eje de la forma republicana de gobierno y factor de ruptura de la estratificación social. A estos asuntos dedicó

Revista de Ciencias Sociales - Número 67 (2015) - Universidad de Valparáíso - ISSN 0716-7725-Valparaíso, Chile 
¿Por qué defendemos la escuela? ¿Acaso está en peligro? ¿Cuál es la escuela que defendemos? ¿Cuál es el peligro que amenaza a la escuela que defendemos?

Puede que venga de inmediato a la mente que estamos reunidos para defender la escuela laica. En parte es verdad y ha sido dicho esta mañana. Pero esto no es todo, hay algo más alto ${ }^{1}$.

Nuestra reunión no debe empobrecerse como si fuese una polémica entre clericales y anticlericales. Esto, sin nombrar que se defiende lo que tenemos. Ahora bien, cestáis en verdad seguros de que en Italia tenemos la escuela laica? ¿Que se pueda defender la escuela laica como si existiera, después del artículo $7^{2}$ ? Pero dejemos esto y avancemos. Defendemos la escuela democrática, la escuela que corresponde a la Constitución democrática que quisimos darnos; la escuela que está en función de esta Constitución, aquella que puede

numerosos escritos y acciones concretas, antes y después de haber colaborado como miembro de la Asamblea Constituyente a levantar la Italia actual.

Si en los años cincuenta del pasado siglo, cuando el sesenta por ciento de la población italiana adulta se confesaba analfabeta y era, pues, imperioso contar efectivamente con una escuela según la Constitución, el problema de la educación pública no ha perdido vigencia en el momento presente. La excelente escuela estatal que Calamandrei ayudó a construir se halla hace algún tiempo amenazada, entre otros factores, por la disminución de los recursos que le asigna el fisco, mientras no se reduce los fondos colectivos que van a parar a establecimientos privados. Como esta constatación, "que da un muy desagradable sabor de actualidad a las palabras de Calamandrei”, según observa De Mauro, Introduzione, cit., pág. 16, adquiere proporciones gigantescas en el contexto chileno de hoy, estimamos indicado que el lector nacional se familiarice con las insidias oligárquicas y trampas antidemocráticas que yacen tras el privilegio privado de la educación, de la mano de un jurista que poseyó cabal conciencia del trasfondo político y social de las instituciones jurídicas. [Nota del Traductor].

1. En sentir de Calamandrei, lo más alto “es percibir y remover las condiciones de incultura que minan profundamente el paso de una democracia puramente formal a una democracia substancial”. De Mauro, Introduzione, cit., pág. 17. [N. del T.].

2. El párrafo primero del artículo 7 de la Constitución italiana establece como uno de los principios fundamentales de la República, que "el Estado y la Iglesia católica son independientes y soberanos cada uno en su propio orden”. [N. del T.].

Facultad de Derecho y Ciencias Sociales - Universidad de Valparaíso - Chile 
ser instrumento para que esta Constitución escrita en papel devenga realidad ${ }^{3}$.

Ved, amigos, yo no soy un pedagogo, no soy un experto en cuestiones escolares. Soy un jurista acostumbrado, por hábito mental, a ver en todos los problemas el aspecto jurídico. Por tanto, también en el problema de la escuela, así como se presenta hoy en este congreso, estaré inclinado a ver los aspectos jurídicos, constitucionales. Lo lamento por el amigo Targhetti ${ }^{4}$, quien ha dicho, con su sólita amabilidad, que se auguraba divertirse al escucharme. No se divertirá, no os divertiréis; sin embargo, intentaré deciros cosas exactas y claras, porque al afrontar y resolver los problemas es necesario, ante todo, tener exacta conciencia de sus términos.

Como yo la veo, la escuela es un órgano «constitucional». Tiene su posición, una importancia propia en el centro de ese conjunto de órganos que forman la Constitución. Como sabéis (pues todos vosotros la habréis leído), en la segunda parte de nuestra Constitución, intitulada «El ordenamiento del Estado», están descritos los órganos a través de los que se expresa la voluntad del pueblo. Son los órganos a través de los que la política se transforma en Derecho, las luchas vitales y sanas de la política se transforman en leyes. Ahora, cuando os viene en mente preguntaros cuáles son los órganos constitucionales, a todos vosotros os vendrá naturalmente como respuesta: son las Cámaras, la Cámara de Diputados y el Senado, el Presidente de la República, la magistratura;

3. Elaborada por una Asamblea Constituyente electa en junio de 1946 y formada por algo más de cinco centenares de diputados que representaron todo el arco político del instante, la Constitución republicana fue promulgada el día 27 de diciembre de 1947 y entró en vigor el primero de enero de 1948. Por ende, en 1950, año del discurso de Calamandrei, era un texto novísimo que tardaría aún en ser implementado legalmente y, sobre todo, pasar del plano normativo a la realidad de las relaciones sociales. Eso explica la frase del autor. Un resumen de la génesis de la Constitución, en Livio Paladin, Diritto costituzionale, Cedam, Padova, 1991, págs. 92-104. [N. del T.].

4. Probablemente, se trata de Ferdinando Targhetti (1882-1968), abogado y compañero de Calamandrei en la Asamblea Constituyente, que Targhetti dirigió como vicepresidente. Fue después diputado del Partido Socialista Italiano, elegido por los votantes de Florencia. [N. del T.].

Revista de Ciencias Sociales - Número 67 (2015) - Universidad de Valparáíso - ISSN 0716-7725-Valparaíso, Chile 
pero no os vendrá a la mente considerar también, entre estos órganos, la escuela, la que, empero, es un órgano vital de la democracia así como nosotros la concebimos. Si hubiese que trazar un parangón entre el organismo constitucional y el organismo humano, habría que decir que la escuela corresponde a los órganos que en el organismo humano tienen la función de crear la sangre. Los órganos hematopoiéticos, aquellos de que parte la sangre que renueva día a día todos los demás órganos, la que lleva a éstos, diariamente, latido tras latido, la renovación y la vida.

La escuela es órgano central de la democracia, porque sirve para resolver lo que para nosotros es el problema central de la democracia: la formación de la clase dirigente. La formación de la clase dirigente, no sólo en el sentido de clase política, esto es, la clase que sesiona en el Parlamento, discute y habla (y acaso grita también), la que ocupa el vértice de los órganos propiamente políticos, sino, además, la clase dirigente en sentido cultural y técnico: los que encabezan las fábricas y empresas, enseñan, escriben, artistas, profesionales, poetas. Este es el problema de la democracia, la creación de esta clase, que no debe ser una casta hereditaria, cerrada, una oligarquía, una iglesia, un clero, una orden. No. En nuestra idea de la democracia, la clase dirigente debe estar siempre abierta y renovarse para que afluyan hacia arriba los mejores elementos de todas las clases, de todas las categorías. Cada clase, cada categoría debe tener la posibilidad de liberar hacia arriba a sus elementos mejores, de modo que éstos puedan temporal, transitoriamente, durante el breve instante de vida que la suerte concede a cada uno de nosotros, contribuir al progreso de la sociedad con su trabajo y sus mejores cualidades personales ${ }^{5}$.

5. En otro escrito sobre la educación, Contro il privilegio dell'istruzione, incluido en el libro Per la scuola, cit., págs. 107-133, Calamandrei es todavía más enfático: "No hay verdadera democracia allí donde, aun siendo todos los ciudadanos igualmente electores y elegibles según el Derecho, en el hecho sólo algunas categorías de ellos disponen de la instrucción suficiente para ser elementos conscientes y activos en la lucha política”. A lo que agrega que "donde la escuela es sólo de quien puede pagársela, acaba por ser de quien puede pagarla también la participación activa en la vida política; y a través del monopolio económico de la instrucción el gobierno deviene en gobierno de los pudientes", mientras que "los pobres son condenados a restar súbditos irresponsables" (págs. 112 y 115). [N. del T.].

Facultad de Derecho y Ciencias Sociales - Universidad de Valparaíso - Chile 
Ya os he dicho que soy un jurista; pero tengo la costumbre, que tal vez me viene un poco de cierta afición toscana por el dibujo bien hecho, de asociar los conceptos jurídicos y políticos a alguna imagen, la que luego me sirve para aficionarme a estos conceptos. Pues bien, cuando pienso en este concepto de la clase dirigente abierta y en continua renovación, que deriva de la afluencia desde abajo de aquellos elementos mejores a que la escuela debe dar la posibilidad de aflorar, me viene en mente (y si aquí hubiera algún colega botánico, que me corrija si cometo un error) cierta plantita, la valisneria, que vive en los pantanos, tiene sus raíces sumergidas en el fondo y no se la ve en la estación invernal, porque está bajo el lodo. Pero cuando llega la primavera, cuando estas raíces que yacen en el fondo perciben a través de las aguas que ha vuelto la primavera, de cada una de estas plantitas comienza a desplegarse un tallo espiral que lentamente se desanuda y alarga hasta llegar a la superficie del pantano, junto a otras mil plantitas que también van en busca del sol. Y cuando cada una llega arriba y siente el aire, florece; y en pocos días la superficie del pantano, que era lóbrega y triste, aparece cubierta por una florescencia, como un prado.

También en la sociedad sucede, tendrá que suceder algo similar. Desde toda la bajura de la originaria suerte humana, desde la incultura original deberá cada quien poder lanzar hacia arriba y desanudar su pequeño tallo para llegar a tomar su parte de sol. Para esto debe servir la democracia, permitir a cada hombre digno tener su parte de sol y de dignidad (aplausos). Sin embargo, esto sólo puede hacerlo la escuela, que es el complemento necesario del sufragio universal. La escuela, que tiene justamente esta característica de alto sentido político, porque sólo ella puede ayudar a elegir y a crear a las personas dignas de ser elegidas, que afloren de todas las clases sociales.

Ved, esta imagen está consagrada en un artículo de la Constitución, siquiera con una fórmula menos imaginativa. Es el artículo 34, donde se dice lo siguiente: "La escuela está abierta a todos. Los capaces y meritorios, incluso si carecen de medios, tienen derecho de alcanzar los grados más altos de los estudios". Este es el artículo más importante de nuestra Constitución. Hay que darse cuenta del valor político y social de este artículo. Seminarium rei publicae, decían los latinos del matrimonio. Nosotros podríamos decirlo de la escuela: seminarium rei 
publicae, porque la escuela forma a los mejores para la renovación continua, cotidiana, de la clase dirigente. Ahora, si esta es la función constitucional de la escuela en nuestra República, preguntémonos cómo está construido este instrumento. ¿Cuáles son sus principios fundamentales? Ante todo, escuela del Estado. El Estado debe constituir sus escuelas. Ante todo, la escuela pública. Antes de exaltar la escuela privada, hay que hablar de la escuela pública. La escuela pública es el prius, la privada, el posterious. Para tener una buena escuela privada es necesario que la del Estado sea óptima (aplausos). Ved, debemos ante todo poner el acento en aquel inciso del artículo 33 de la Constitución que dice así: "La República dictará las normas generales sobre la instrucción e instituirá escuelas estatales para todas las categorías y todos los grados". Con que por este inciso - excusadme si os hago una suerte de comentario exegético, algo pedantesco- el Estado, en materia escolar, tiene ante todo una función normativa. El Estado debe poner los principios generales de la legislación escolar. Luego, e inmediatamente, el Estado tiene una función de realización. El Estado no se debe limitar a poner los principios platónicos, ideales, teóricos de la constitución de las escuelas. Las debe constituir conforme y fielmente a estos principios; ha de instituir, hacer realidad todas las escuelas y de todas las categorías. Y esto no lo debe hacer a título casi diría de muestrario. El Estado no debe decir: yo hago una escuela que sirva de modelo; el resto que lo hagan otros. No; la escuela está abierta a todos, y si todos quieren frecuentar la escuela estatal, en todas las categorías escolares tendrá que haber tantas escuelas óptimas, que correspondan a los principios puestos por el Estado, escuelas públicas que permitan recoger a todos aquellos que acuden al Estado para ir a sus escuelas. La escuela está abierta a todos. El Estado, pues, debe constituir escuelas óptimas para acoger a todos. Esto está escrito en el artículo 33 de la Constitución. La escuela del Estado, la escuela democrática, es una escuela que tiene carácter unitario, es la escuela de todos, crea ciudadanos, no crea católicos, protestantes ni marxistas. La escuela es la expresión de otro artículo de la Constitución, el artículo 3: "Todos los ciudadanos tienen paridad social y son iguales ante la ley, sin distinción de sexo, raza, lengua, religión, opinión política, condiciones personales y sociales". Y el artículo 51: "Todos los ciudadanos pueden acceder a los empleos públicos y a los

Facultad de Derecho y Ciencias Sociales - Universidad de Valparaíso - Chile 
cargos electivos en condiciones de igualdad, según los requisitos establecidos por la ley". La escuela del Estado debe ser instrumento de estos dos artículos, instrumento de esta igualdad cívica, de este respeto por la libertad de todos los credos y todas las opiniones. Este instrumento es la escuela pública, democrática, de la que un querido amigo, Guido Calogero, ha dicho con exactitud lo siguiente:

A través de la estructura de los programas y del método didáctico, y la plena apertura de la escuela a docentes y estudiantes de todas las convicciones y religiones, sin parcial preferencia alguna por unos u otros, la escuela pública asegura que toda voz esté presente; que ninguna verdad sea enseñada sin ser ante todo puesta en duda en la tranquila confrontación con las verdades opuestas; que la adquisición de las convicciones tenga lugar, no bajo la presión de una mentalidad dogmática, sino en el espíritu de la libre discusión crítica, la única capaz de no hacer olvidar los derechos simultáneos de las convicciones ajenas ${ }^{6}$.

Cuando la escuela pública es así de fuerte y segura, entonces, pero sólo entonces, la escuela privada no es peligrosa. Entonces, pero sólo entonces, la escuela privada puede ser un bien. Puede ser un bien que fuerzas privadas, iniciativas pedagógicas de clases, grupos religiosos,

6. Guido Calogero (1904-1986), filósofo, catedrático, académico y político, dedicó parte de su ingente obra a la escuela y el problema de la educación en general, como los ensayos La scuola dell'uomo, Sansoni, Firenze, 1939, con varias ediciones y reediciones, y Scuola sotto inchiesta, Einaudi, Torino, 1965. Procedente del socialismo liberal, durante algún tiempo militaría con Calamandrei en el Partito d'Azione, formado clandestinamente hacia 1942 en la lucha contra el régimen fascista. Acerca de la actividad política del último bajo la dominación de los camisas negras, véase Alessandro Galante Garrone, Calamandrei. Il profilo biografico, intelettuale e morale di un grande protagonista della nostra storia, Garzanti, Milano, 1987, págs. 77-92, y la recensión castellana de esta obra por Manuel de Ricavoba y Rivacoba, en el Anuario de Filosofía Jurídica y Social, publicación de la Sociedad Chilena de Filosofía Jurídica y Social, número 5, Edeval, Valparaíso, 1987, págs. 275-277. En página 77, su biógrafo recuerda esta descripción de Norberto Bobbio de la actitud que Calamandrei asumió desde el principio e instintivamente frente al fascismo, la de un opositor "firmísimo, intransigente, despectivo". [N. del T.].

Revista de Ciencias Sociales - Número 67 (2015) - Universidad de Valparáíso - ISSN 0716-7725-Valparaíso, Chile 
políticos, filosofías o corrientes culturales cooperen con el Estado para ensanchar, estimular y renovar la cultura con una variedad de iniciativas. $\mathrm{Al}$ derecho de la familia de instruir y educar a los hijos, que está consagrado en otro artículo de la Constitución, el artículo 30, corresponde la oportunidad que debe darse a las familias de inscribir a sus retoños en escuelas de su agrado y, por tanto, permitir la institución de las escuelas que correspondan mejor - con ciertas garantías que veremos a continuación- a las preferencias políticas, religiosas o culturales de aquella familia. Sin embargo, hay que tener cabal conciencia de que mientras la escuela pública es expresión de unidad, cohesión e igualdad cívica, la escuela privada es expresión de variedad, la que puede significar heterogeneidad de corrientes descentradas, que el Estado tiene el deber de impedir que se conviertan en corrientes disgregadoras. En otras palabras, la escuela privada no es creada para esto.

La escuela de la República, la escuela del Estado, no es la escuela de una filosofía, una religión, un partido o una secta. Por tanto, para que, al surgir, las escuelas privadas puedan ser un bien y no un peligro, se requiere: 1) que el Estado las vigile y controle, y que sea neutral, imparcial entre ellas. Que no favorezca a un grupo de escuelas privadas en perjuicio de otras; 2) que las escuelas privadas cumplan ciertos requisitos mínimos de seriedad en su organización. Sólo así, y con modalidades más precisas de las que hablaré dentro de poco, se puede tener la ventaja de la coexistencia de la escuela pública con la escuela privada. Esto es, la competencia entre las escuelas estatales y las escuelas privadas. Que se establezca una competencia entre las escuelas públicas y las escuelas privadas, de modo que el Estado, a la luz de las escuelas privadas que surjan y puedan eventualmente aportar ideas y realizaciones que hasta ese punto no existían en las escuelas públicas, se sienta estimulado a mejorar, a tornar — séame permitida la expresión- «más óptimas» sus propias escuelas. La escuela privada debe ser un estímulo para el Estado, no un motivo de abdicación.

Que haya incluso escuelas de partido o escuelas de iglesia. Pero el Estado las debe vigilar y regular; las debe mantener dentro de sus límites y conseguir que sean mejores. En suma, la escuela del Estado debe ser una garantía para que no se caiga en lo que sería el fin de la

Facultad de Derecho y Ciencias Sociales - Universidad de Valparaíso - Chile 
escuela y quizá el fin de la democracia y la libertad, o sea, la escuela de partido.

¿Cómo se hace para establecer en un país la escuela de partido? Se puede hacer de dos maneras. Una es la del totalitarismo abierto, declarado. La hemos experimentado, iay de mí! Creo que todos vosotros la recordaréis, aunque mucha gente no la recuerde más. La experimentamos bajo el fascismo. Todas las escuelas devienen escuelas del Estado; la escuela privada deja de estar permitida, pero el Estado se convierte en un partido y, por tanto, todas las escuelas son escuelas del Estado, aunque a causa de esto son, además, escuelas de partido. Sin embargo, existe otra forma para llegar a transformar la escuela del Estado en escuela de partido o de secta. El totalitarismo fraudulento, indirecto, lento, como ciertas pulmonías que llegan sin fiebre, pero son peligrosísimas. Hagamos la hipótesis, así, en abstracto, de que haya un partido en el poder, un partido dominante que, empero, pretende en las formas respetar la Constitución, no violarla en su substancia. No quiere hacer la marcha sobre Roma y transformar las aulas en alojamiento para los manípulos, pero quiere establecer, sin aparentarlo, una dictadura larvada. Entonces, ¿qué hay que hacer para apoderarse de las escuelas y transformar las escuelas del Estado en escuelas de partido? Nota que las escuelas del Estado tienen el defecto de ser imparciales. Hay una cierta resistencia; en estas escuelas la hay siempre, incluso bajo el fascismo la hubo. Entonces, el partido dominante sigue otro camino (entendámonos, esta es una hipótesis teórica).

Comienza a descuidar las escuelas públicas, a desacreditarlas, empobrecerlas. Deja que se desangren y empieza a favorecer a las escuelas privadas. No todas las escuelas privadas. Las escuelas de su partido, de ese partido. Y entonces, todos los cuidados comienzan a ir hacia estas escuelas privadas. Cuidados en dinero y privilegios. Incluso se comienza a aconsejar a los muchachos que vayan a estas escuelas, porque, en el fondo, son mejores — así se dice- que las del Estado. Y acaso se otorga premios, como ahora os diré, o se propone otorgar premios a aquellos ciudadanos que estén dispuestos a mandar a sus retoños a las escuelas privadas en vez de las escuelas públicas. A «esas» escuelas privadas. Los exámenes son más fáciles, se estudia menos y sale mejor. Así, la escuela privada deviene una escuela privilegiada. No

Revista de Ciencias Sociales - Número 67 (2015) - Universidad de Valparáíso - ISSN 0716-7725-Valparáiso, Chile 
pudiendo transformar abiertamente las escuelas del Estado en escuelas de partido, el partido dominante arruina las escuelas del Estado para dar la prevalencia a sus escuelas privadas.

iAtención, amigos, este es el punto que se precisa discutir en este congreso! iAtención, que esta es la receta! iHay que tener bajo la mirada a los cocineros de esta baja cocina!

La operación se realiza de tres maneras: 1) os lo he dicho ya: arruinar las escuelas del Estado. Dejar que se derrumben. Empobrecer sus presupuestos. Ignorar sus necesidades. 2) Atenuar la vigilancia y el control de las escuelas privadas. No controlar su seriedad. Dejar que enseñen allí docentes que no tienen los títulos mínimos para enseñar. Dejar que los exámenes sean una chanza. 3) Dar a las escuelas privadas dinero público. Este es el punto. iDar a las escuelas privadas dinero público! Es el método más peligroso, la fase más peligrosa de toda la operación. Y considerad que es ya ampliamente empleado, si no precisamente en el campo de la escuela, sí, por ejemplo, en el campo de los socorros escolares, donde hay cifras inauditas, increíbles, decenas de miles de millones que salen de la caja del Estado, pero solamente de dos mil millones se puede saber adónde fueron a parar y si llegaron a las escuelas públicas. Dónde hayan terminado los demás millones, no lo sabemos. Sólo podemos imaginarlo, y no hace falta mucha fantasía.

Este, pues, es el punto, el punto más peligroso del método. Dinero de todos los ciudadanos, todos los contribuyentes, todos los creyentes de diversas religiones, todos quienes pertenecen a distintos partidos, el que, en cambio, es destinado a alimentar las escuelas de una sola religión, una sola secta, un solo partido.

Os daréis cuenta de que en la catastrófica situación en que se halla la escuela pública, se llega a cifras pavorosas. Se habla de la instrucción obligatoria, pero en Italia hay más de dos millones de muchachos que se substraen a la instrucción obligatoria escolar porque faltan cincuenta mil salas de clases; y, al mismo tiempo, se verifica una cosa realmente maravillosa. En Italia hay desocupación entre los maestros. En Italia, donde hay tantos muchachos a los que falta la instrucción fundamental, ihay cuarenta mil maestros desocupados porque faltan escuelas!

Por ende, en esta situación trágica es una locura, un delito pensar que el Estado, en vez de concentrar en la escuela pública todos los

Facultad de Derecho y Ciencias Sociales - Universidad de Valparaíso - Chile 
recursos del pequeño ítem presupuestario de la instrucción (pequeño en comparación con otras partidas presupuestarias que sabéis cuáles son), se ponga a repartir el dinero a las escuelas privadas.

En los Estados en que la escuela privada florece, son los particulares quienes dan su contribución de riqueza al Estado para acrecentar la vitalidad escolar de la nación. No es al revés, o sea, que Estado olvide hacer el mínimo necesario para su propia escuela y, luego, desperdicie sus escasos fondos en esta suerte de proteccionismo escolar que consiste en dar subsidios a las escuelas privadas.

Para precaver este peligro no se requería mucha astucia. Durante los trabajos de la Asamblea Constituyente se puso esta disposición en el artículo 33 de la Constitución: "Entidades y personas privadas tienen derecho de establecer escuelas e institutos de educación, sin carga para el Estado".

Como sabéis, esta fórmula nació de un compromiso; y como todas las fórmulas nacidas de compromisos, hoy ofrece el flanco a interpretaciones sofísticas, como la de quien sostiene que, en virtud de este artículo 33, un particular, si quiere establecer una escuela, no puede acudir al Estado para ser subsidiado en el momento inicial, pero, una vez establecida la escuela, el artículo no prohíbe que quepa dirigirse al Estado para obtener sucesivamente un subsidio. Y pese a que tal derecho no existe, el hecho es que se presenta solicitudes al Estado, en algunos casos de buena fe. El Estado, si quiere, puede dar un subsidio a las escuelas ya establecidas.

Ahora, yo creo que, dado este texto, así como es, no se puede negar que en casos excepcionalísimos el Estado puede dar un subsidio a escuelas privadas. El artículo 33 dice solamente que no hay un derecho, pero es necesario que aclaremos este concepto. En consecuencia, me parece que debemos empeñarnos, y debéis empeñaros vosotros en el Congreso, donde también discutiréis este punto, en reclamar que en la próxima reforma de este artículo se lo complete con disposiciones que garanticen que estos subsidios del Estado a las escuelas privadas puedan ser otorgados sólo en casos excepcionalísimos y a través de procedimientos de control, no ya con el solo beneplácito del ministro, quien es ciertamente persona imparcial, pero podría ser sucedido por un ministro que no sea imparcial. Por ende, subsidio, sí, pero con un control

Revista de Ciencias Sociales - Número 67 (2015) - Universidad de Valparáíso - ISSN 0716-7725-Valparaíso, Chile 
preciso de órganos en todo lo posible independientes. Yo pienso que podría ser la comisión legislativa para la instrucción de la Cámara o del Senado.

Este u otro sistema que se excogite, es un problema que hay que examinar atentamente

Pero hay otra cuestión que se ha manifestado y que podría permitir que se embrolle a la ley. Se trata de eso que los juristas llamamos «fraude a la ley», aquel quid que los clientes solicitan a los causídicos de pocos escrúpulos, a quienes acuden para saber cómo se puede violar la ley fingiendo observarla. Es extraño que en ciertos documentos oficiales, indudablemente que sin mala voluntad, se deslicen frases que pueden hacer pensar en esta figura tan conocida del fraude a la ley.

Ha aparecido así la idea de la asignación familiar, la asignación familiar escolar

Dijo el ministro de Instrucción al Congreso Internacional de Institutos Familiares lo siguiente: la escuela privada debe servir para «estimular» al máximo los gastos no estatales para la enseñanza, aunque eso no excluye que el Estado dé subsidios a las escuelas privadas. Sin embargo, agregó esto: pensad, si un padre quiere mandar a su hijo a la escuela privada, tiene que pagar tasas. $\mathrm{Y}$ este padre es un ciudadano que ha ya pagado, como contribuyente, su tasa para participar en el gasto que el Estado eroga para las escuelas públicas. Por ende, este pobre padre debe pagar dos veces la tasa. Entonces, para aliviarlo de esta doble carga, se da una asignación familiar a este benemérito ciudadano que quiere mandar a su hijo a la escuela privada.

Quien quiere mandar a su hijo a la escuela privada, acude entonces al Estado y obtiene un subsidio, una asignación

El ministro ha dicho que "es un tema que, por su novedad, no puede no dar motivo a incertidumbres y pareceres discordantes". Faltaba más. Sin embargo, confío en que vosotros no discordaréis y estaréis

Facultad de Derecho y Ciencias Sociales - Universidad de Valparaíso - Chile 
todos en contra, porque es un razonamiento basado en un sofisma. iEl ciudadano que paga dos veces! Mandar al propio hijo a la escuela privada es un derecho, lo dice la Constitución; pero des un derecho que se lo haga pagar? Es un derecho que uno mismo ejerce si así lo quiere, pero a su propio cargo. El ciudadano que quiere mandar a su hijo a la escuela privada, que la pague; si no, que lo mande a la escuela pública.

Por trazar un parangón, en el campo de la justicia se podría hacer un discurso semejante. Sabéis que para obtener justicia hay jueces públicos; no obstante, los ciudadanos tienen derecho de hacer decidir sus controversias también por jueces árbitros. Pero el arbitraje cuesta caro, a menudo centenares de miles de liras. Sin embargo, inunca ha venido a la mente de un ciudadano que prefiera el arbitraje a los jueces públicos, acudir al Estado para pedirle un subsidio con la finalidad de pagar a los árbitros!

Ahora bien, el razonamiento, que no es obra del ministro, sino de quien le preparó estas argumentaciones, es incoherente y no tiene en cuenta la realidad jurídica de las normas a que se refiere. Notad que el mismo ministro, y esto es lo más grave y singular, ha invocado el artículo 34 de la Constitución. Ha dicho que "esta asignación familiar a las personas que mandan a sus hijos a la escuela privada, la permite la Constitución, que para eso está el artículo 34”. El artículo 34, después de enunciar que los individuos capaces y meritorios tienen el derecho de recibir instrucción, incluso la más elevada, agrega que para hacer efectivo este derecho la República establecerá becas de estudio, asignaciones a las familias y otras previsiones, que deben ser adjudicadas mediante concurso. Pero, ¿qué tiene que ver el artículo 34 con las asignaciones familiares? Este artículo prevé solamente que haya jóvenes que posean especiales aptitudes para continuar los estudios y que se les deba proporcionar los medios mediante concurso. Aquí se ha tratado de cambiar las cartas de la baraja.

Por lo tanto, si fuese adoptado, este juego de las asignaciones familiares sería una especie de incitación pagada a desertar de las escuelas del Estado y, en consecuencia, un modo indirecto de favorecer a ciertas escuelas, un premio para quien manda a sus hijos a ciertas escuelas privadas donde se fabrica, no ciudadanos, ni siquiera creyentes de cierta religión, lo que podría ser una cosa respetable, sino electores de cierto partido. 


\section{Luego, en la reforma está la cuestión de la paridad}

El artículo 33 de la Constitución, en el párrafo que se refiere a la paridad, dice lo siguiente: "Al fijar derechos y obligaciones de la escuela no estatal que pide paridad, la ley debe asegurarle plena libertad, un tratamiento equivalente al de las escuelas estatales".

Como sabéis, también esta palabra, paridad, resultó de un compromiso político. Primero se habló de igualación, parificación, palabras que tenían un significado preciso. Luego se prefirió en el artículo de la Constitución la palabra paridad.

Sí, paridad; pero hay que recordar que, ante todo, antes de conceder la paridad, el Estado - lo dice el propio artículo 33- debe fijar los derechos y obligaciones de la escuela a que concede esta paridad, y que según otro párrafo del mismo artículo el Estado tiene la incumbencia de dictar las normas generales sobre la instrucción. Por ende, esta paridad no puede significar renuncia a garantizar y controlar la seriedad de los estudios, programas, títulos de los docentes, pruebas. En resumen, es preciso evitar el nauseabundo, repugnante sistema que consiste en favorecer en las escuelas la competencia a la baja, o sea, que el Estado favorezca no sólo la competencia de la escuela privada con la escuela pública, sino que apoye esta competencia privilegiando la escuela donde se enseña peor, con un auténtico incentivo oficial a la bestialidad.

\section{En la Exposición de motivos de la reforma ha aparecido otra idea y un nuevo parangón jurídico}

El ministro Gonella tiene a un mal abogado como consejero, porque cada vez que habla de asuntos jurídicos dice cosas que no tienen fundamento alguno ${ }^{7}$. En la Exposición de motivos se dice que, como

7. Guido Gonella (1905-1982), periodista y político graduado en Filosofía, fue miembro de la mayoría democratacristiana de la Asamblea Constituyente y, de 1946 a 1951, ministro de Educación Pública en el gobierno de Alcide De Gasperi (1881-1954). De 1953 a 1968 ocuparía varias veces el cargo de ministro de Justicia. [ $N$. del T.].

Facultad de Derecho y Ciencias Sociales - Universidad de Valparaíso - Chile 
en la Constitución está el derecho a la escuela privada, la consecuencia (son palabras de la Exposición) es que se debe considerar que para abrir una escuela privada ya no es necesaria la autorización preventiva, la cual de ahora en adelante podría ser substituida por la «notificación», análogamente a lo que establece la ley de prensa. En otros términos, cada ciudadano o entidad que se propongan abrir una escuela privada, deberán notificar la apertura a la autoridad escolar, y será tarea de ésta comprobar a continuación si se cumplen algunas condiciones inderogables relativas sea al sujeto que abre la escuela, sea a la propia escuela.

Ahora, ¿qué tiene que ver esta cuestión de la libertad de la escuela privada con la libertad de prensa? En materia escolar, ante todo, está el deber y el poder del Estado de establecer sus escuelas. El Estado tiene el deber de enseñar, no el de publicar o imprimir. La prensa puede ser una actividad reservada enteramente a los particulares. Pero la escuela debe ser, ante todo, una actividad, una función que el Estado desarrolla por sí mismo, debe desarrollarla en el modo que he indicado, y la actividad escolar privada es sólo un complemento de la actividad escolar del Estado. Es el Estado el que debe instituir escuelas, establecer el nivel escolar de los estudios y cerciorarse de que las otras escuelas correspondan a este nivel. En fin, también en el parangón con la libertad de prensa hay un truco abogadil. El artículo 21, cuando dice que la prensa no puede ser sujeta a limitación, tampoco excluye que las leyes establezcan para la prensa una serie de limitaciones preventivas.

$\mathrm{Ni}$ siquiera para la prensa es siempre verdad que este derecho se pueda ejercer sin autorización preventiva alguna, bastando sólo una notificación.

Ahora, no hay un artículo que diga que la escuela privada no puede ser sometida a limitaciones.

La reforma de la escuela merece una discusión profunda y serena. Desde afuera se ve muchas cosas bonitas. Humo, escenarios, encuestas, cuestionarios. Ha trabajado una comisión de muchos miembros. Han ocupado un edificio y en éste han trabajado intensamente. Pasando por ahí se veía las luces siempre encendidas, que hacían recordar las luces del Palacio Venecia cuando se pasaba bajo sus ventanas ${ }^{8}$.

8. El Palacio Barbo o Venecia, edificio renacentista que se levanta junto a la plaza homónima en el centro de Roma, fue ocupado hacia finales de la tercera

Revista de Ciencias Sociales - Número 67 (2015) - Universidad de Valparáíso - ISSN 0716-7725-Valparáiso, Chile 
Sin embargo, esta reforma me da la impresión de esas estampas que estaban de moda cuando yo era muchacho. En esas estampas se veía bosques, árboles, estanques, montes, todo un amasijo de ramas y pájaros y otras muchas cosas lindas, bajo lo cual estaba escrito: encontrad al cazador. Entonces, a fuerza de buscar, en un rinconcito se hallaba al cazador apuntando el fusil. También en la reforma aparece el cazador apuntando el fusil. Es la escuela privada, que quiere transformarse en escuela privilegiada. Este es el punto que cuenta. Todo lo demás, cifras astronómicas de billones, acontecerá en el lejano porvenir; pero la escuela privada, si no estáis atentos, será efectiva realidad mañana. La escuela privada se transforma en escuela privilegiada y desde aquí comienza la escuela totalitaria, la transformación de la escuela democrática en escuela de partido.

En fin, existe otro peligro, acaso más grave todavía. Es el peligro de la descomposición moral de la escuela

Este sentimiento de desconfianza, de cinismo más que de escepticismo, que se va difundiendo en la escuela, especialmente entre los jóvenes, es muy significativo. Es el ocaso de las viejas ideas sobre la escuela de Gaetano Salvemini y Augusto Monti: seriedad, precisión, honestidad, puntualidad ${ }^{9}$. Estas simples ideas. Cumplir con el propio deber, hacer clases. Y que la escuela sea escuela del carácter, formadora de conciencias, de personas honestas y leales. Se va difundiendo la idea de que todo esto está superado, que ya no vale más. Hoy valen apoyos,

década del siglo XX por el líder del fascismo para establecer allí su cuartel general. La propaganda del gobierno decía que las luces de la oficina de Mussolini permanecían siempre encendidas, en señal de que éste no descansaba nunca. [N. del T.].

9. Los escritos sobre la escuela de Gaetano Salvemini (1873-1957), historiador y político antifascista, llenan un grueso volumen de sus Opere, Feltrinelli, Milano, t. V (Scritti sulla scuola), 1966. En uno de ellos, intitulado Che cosa è la laicità, denunció tempranamente la amenaza política consistente en favorecer las escuelas confesionales y deprimir la escuela pública. Augusto Monti (1889-1966), pedagogo antifascista y de pensamiento laico, como Salvemini, se ocupó de la reforma escolar en su ensayo Scuola classica e vita moderna, Arnaldo Pittavino, Torino, 1923. Al igual que Calamandrei, participó en la Resistencia contra el fascismo en el Partido de Acción. [N. del T.].

Facultad de Derecho y Ciencias Sociales - Universidad de Valparaíso - Chile 
recomendaciones, carnets de un partido o una parroquia. La religión, una cosa seria en sí misma, acaso la más seria de todas, porque la cosa más seria de la vida es la muerte, se convierte en un desagradable pretexto para que cada quien haga sus propios negocios.

Este es el peligro. La descomposición moral de la escuela. No es la escuela de curas lo que nos asusta, porque hace cien años había escuelas de curas en que se sabía enseñar el latín y el italiano, de las que salieron hombres como Giosuè Carducci ${ }^{10}$. Lo que asusta sobre todo son los deshonestos, los hombres sin carácter, sin fe, sin opiniones. Estos hombres que hace diez años eran fascistas, hace cinco eran antifascistas en las palabras y ahora se han vuelto, bajo los más variados nombres, fascistas en la substancia, esto es, logreros del régimen.

Y hay otro peligro todavía, dejarse vencer por el desaliento ${ }^{11}$. Pero no es preciso dejarse vencer por el desaliento. Ved, con razón se dijo que quien venció la guerra de 1918 fue la escuela media italiana, porque esos muchachos, cuyos cadáveres yacen todavía en el Carso, habían salido de nuestras escuelas, nuestros liceos y nuestras universidades ${ }^{12}$. Pero mirad también qué cosa sucedió durante la Resistencia y la

10. 1835-1907. Fue el poeta predilecto de Calamandrei en la época del liceo, según registra Galante Garrone, op. cit., cfr. pág. 30. [N. del T.].

11. Coincidente con el período que el autor llamó de «desistimiento» (desistenza), sucesivo a la Resistencia, o sea, el retorno del conformismo, la pereza, el escepticismo, el debilitamiento de la voluntad reformadora, que para Calamandrei comenzó pronto, inmediatamente después de la liberación de Italia de la zarpa totalitaria. En su opinión, "el peligro no está en los colaboradores, miembros de las redadas y torturadores del viejo régimen, pese a que ahora han vuelto a circular por las plazas, sino en nosotros, en nuestra facilidad para el olvido, en la desconfianza, el deseo de apartarse, dejar la política a los politicastros”. Galante Garrone, op. cit., pág. 265. [N. del T.].

12. El Carso es un altiplano formado por roca calcárea que se extiende desde el nordeste de Italia, pasando por Eslovenia, hasta la parte noroccidental de Croacia. Durante la Primera Guerra Mundial, en el frente del río Isonzo, los ejércitos italiano y austro-húngaro libraron de 1915 a 1917 cruentas batallas, que cobraron la vida a cientos de miles de soldados de ambos bandos. Calamandrei combatió como voluntario toda la Gran Guerra. Lo alarmaron especialmente la ofensiva austríaca de 1916 en los altiplanos y, sobre todo, la terrible derrota de Caporetto. Al final, tuvo la

Revista de Ciencias Sociales - Número 67 (2015) - Universidad de Valparáíso - ISSN 0716-7725-Valparáiso, Chile 
Liberación. Sucedió lo mismo. Hubo profesores y maestros que dieron ejemplos admirables, desde la cárcel hasta el martirio. Una maestra que por largos años enfrentó serenamente la galera fascista, está aquí entre nosotros.

Y todos nosotros, viejos docentes, llevamos en el corazón el nombre de nuestros estudiantes que supieron resistir las torturas, que dieron su sangre por la libertad de Italia.

Pensemos en estos muchachos que salieron de nuestras escuelas y no desesperemos del porvenir.

Seamos fieles a la Resistencia, amigos. Hay que continuar defendiendo en las escuelas la Resistencia y la continuidad de la conciencia moral

satisfacción de ser el primer oficial italiano en entrar a la reconquistada ciudad de Trento.

Durante esos años descubrió y solidarizó con el mundo de los desheredados, el pueblo humilde y en su mayoría analfabeto que había luchado instintivamente por una causa que apenas conseguían entender las personas cultas y educadas. Pronto se galvanizará también en él una indignada rebelión contra las injusticias sociales, el egoísmo de los ricos y los privilegios reservados a algunos que bloquean el desarrollo de los desfavorecidos. Cfr. Galante Garrone, op. cit., págs. 38-53, y De Mauro, Introduzione, cit., pág. 23 [N. del T.].

Facultad de Derecho y Ciencias Sociales - Universidad de Valparaíso - Chile 